\title{
Peran Levers of Control Terhadap Hubungan Antara Perencanaan Strategis dan Kinerja UMKM
}

\author{
Praja Hadi Saputra ${ }^{\mathrm{a}}$, Hamid Bone ${ }^{\mathrm{b}}$, Indah Permatasaric \\ ${ }^{a}$ Universitas Muhammadiyah Kalimantan Timur, ${ }^{b, c}$ Universitas Mulawarman Samarinda \\ apraja.hs@umkt.ac.id, bhamidbone@feb.unmul.ac.id, 'beeindah@gmail.com
}

\begin{abstract}
Abstrak - Penelitian ini menginvestigasi peran sistem pengendalian berbasis levers of control dalam hubungan Antara formulasi strategis dan kinerja UMKM yang ada di Kota Samarinda. Melalui survei yang dilakukan terhadap pimpinan (kontroler) UMKM di Kota samarinda, penelitian ini memberikan bukti tentang peran sistem pengendalian manajemen dalam hubungan antara formulasi steategi dengan kinerja UMKM. Dari 49 respon para pimpinan UMKM yang diolah menggunakan teknik analisis SEM-PLS, hasil penelitian ini memberikan bukti empiris yang menunjukkan bahwa formulasi strategi dalam perencanaan strategis UMKM memiliki hubungan positif dengan kinerja UMKM. Begitu juga hubungan tidak langsung keduanya (mediasi) melalui sistem pengendalian manajemen berbasis Levers of Control (LOC) yang menunjukkan keterdukungan terhadap hipotesis mediasi bahwa ssstem pengendalian manajemen (berbasis LOC) memiliki pengaruh dalam hubungan antara formulasi strategi dengan kinerja UMKM di Kota Samarinda. Dengan kata lain, dapat disimpulkan bahwa sistem pengendalian manajemen mampu meningkatkan peranan formulasi strategi yang berujung pada peningkatan kinerja organsiasi UMKM.
\end{abstract}

Kata Kunci - formulasi strategi; levers of control; kinerja organisasi; sistem pengendalian manajemen

\begin{abstract}
This study investigates the role of levers-of-control (LOC) based controlling system in the strategy formulation and MSME performance relationship in Samarinda. Through a survey conducted on the leadership (controller) of MSMEs in Samarinda City, this study evidenced the role of management control systems in the strategy formulation and MSME performance relationship. Of the 49 responses of MSME leaders, processed using PLS-SEM analysis, this study provided empirical evidence that the strategy formulation had a positive relationship with MSME performance. In addition, the indirect relationship between the two (mediation) through LOC-based management system supported the mediation hypothesis that the LOC-based management control system affects the strategy formulation and MSME performance relationship. In other words, it can be concluded that the management control system can increase the strategy formulation role that leads to MSME performance betterment.
\end{abstract}

Keywords - strategy formulation; levers of control; organizational performance; management control system

\section{PENDAHULUAN}

Usaha Mikro, Kecil dan Menengah (UMKM) dewasa ini dirasakan sudah menjadi urgensitas untuk segera diperdayakan mengingat peran UMKM sebagai salah satu pilar pertumbuhan ekonomi bangsa khususnya di Indonesia. UMKM juga memiliki potensi yang besar untuk menggerakkan kegiatan ekonomi masyarakat dan menjadi sumber pendapatan sebagian besar masyarakat dalam meningkatkan kesejahteraanya. UMKM dikatakan sebagai pilar pertumbuhan ekonomi dengan melihat kontribusi yang diberikan semakin besar dari tahun ke tahun. Fakta pendukung terhadap penjelasan tersebut adalah jumlah UMKM Indonesia yang termasuk paling besar di bandingkan dengan negara lain. Pada Tahun 2016, berdasarkan sensus ekonomi, ada sekitar 400.000 UMKM yang tersebar di Indonesia. Jumlah tersebut dipengaruhi oleh faktor pertumbuhan penduduk yang berusia produktif sehingga butuh lapangan pekerjaan dalam jumlah yang besar dan terbukti UMKM membantu penyerapan tenaga kerja dalam negeri yang tumbuh dari 96,99\% menjadi 97,22\% dalam lima tahun terakhir. Terkait dengan kontribusi UMKM pada Produk Domestik Bruto (PDB), Kementrian Koperasi dan UKM mencatat terjadinya peningkatan dari $57,84 \%$ menjadi $60,34 \%$ di tahun 2016.

Fakta mengenai kontribusi, peranan, dan majunya UMKM sebagai tonggak pertumbuhan ekonomi dan pembangunan nasional tidak luput dari berbagai permasalahan yang perlu menjadi perhatian dari berbagai pihak. Riyadi (2001) mengungkapkan bahwa terdapat beberapa permasalahan pokok yang dihadapi UMKM seperti rendahnya produktivitas yang dimiliki, sumber daya manusia dan manajemen yang belum profesional serta kurangnya respon UMKM terhadap kemajuan teknologi yang kiat pesat. Permasalahan tersebut tentunya dapat diatasi jika para pelaku UMKM mampu mengembangkan bisnis mereka secara kreatif dan inovatif dengan tetap menjadikan pasar, kualitas, produktivitas serta daya saing sebagai orientasi pengembangan usaha. 
Samarinda sebagai ibukota Propinsi Kalimantan Timur mengarahkan pembangunan pada sektor prekonomian yang nantinya dapat memberikan kesejahteraan bagi penduduknya. Arah pembangunan tersebut salah satunya dengan memperdayakan UMKM yang ada. Perkembangan industri kecil dan menengah di Kota Samarinda dirasakan juga semakin pesat sehingga berimplikasi pada persaingan yang juga semakin kompetitif. UMKM yang tidak memiliki daya saing yang baik maka akan gugur dengan sendirinya akibat "seleksi alam" dalam dunia bisnis khususnya persaingan pada industri kecil dan menengah. Oleh karena itu, perlu adanya implementasi perencaan strategis dan sebuah sistem pengendalian manajemen (SPM) yang bertumpu pada karakteristik relevan bagi UMKM sehingga dapat meningkatkan kinerja dan daya saing usahanya. Penelitian ini merupakan salah satu jawaban pasti untuk memberikan pedoman empiris untuk menyelesaikan permasalah tersebut.

Perkembangan studi tentang pengendalian manajemen dirasakan sangat dinamis serta erat kaitannya dengan pertumbuhan ekonomi, perubahan lingkungan industri yang tidak menentu serta faktorfaktor lingkungan lain yang menuntut organisasi untuk menyesuaikan sistem manajemen yang digunakan. Sebuah usaha atau organisasi bisnis yang dibentuk dengan tujuan tertentu diharuskan mampu untuk memanfaatkan sumber daya yang dimiliki agar dapat memenangkan persaingan bisnis, memaksimalkan keuntungan, serta menjawab tantangan-tantangan serta memanfaatkan peluang dalam menjalankan bisnisnya (Jumaili dan Gudono, 2006). Para pelaku usaha dituntut untuk berkompetisi dalam merealisasikan strategi mereka dengan menciptakan sesuatu yang berbeda sehingga mampu menyesuaikan diri dengan market competition atau persaingan pasar yang dihadapinya (Porter, 1999). Fokus utama dari perencaan strategis dalam penelitian ini adalah formulasi atau proses pembentukan strategi organisasi bisnis atau UMKM karena dianggap berhubungan erat dengan proses pengendalian manajemen organisasi. Peranan Sistem Pengendalian Manajemen (SPM) dilihat dari konsep strategi sebagai sebuah pendekatan berproses (Kober dkk., 2007; Roberts, 1990) dan sistem pengendalian manajemen perlu disesuaikan dengan strategi organisasi itu sendiri (Kober dkk., 2007).

Berdasarkan pada penjelasan latar belakang sebelumnya, proposal penelitian ini kemudian memberikan rumusan masalah yaitu tentang bagaiamanakan peranan dari Sistem Pengendalian
Manajemen (SPM) yang diterapkan oleh UMKM dalam merumuskan atau memformulasikan strategi usaha sehingga nantinya dapat meningkatkan kinerja bisnis atau organisasi UMKM?. Selain itu, rumusan masalah selanjutnya adalah apakah peran dari SPM tersebut dapat mendistorsi pengaruh dari perencanaan strategis terhadap kinerja organsiasi UMKM (meningkat atau termitigasi)?.

Dengan melihat persepsi para manajer atau pempinan UMKM di Kota Samarinda melalui survei, penelitian ini ingin menguji hubungan antara formulasi strategi (emergent dan intended) yang merupakan bagian dari perencanaan strategis dengan penggunaan Sistem Pengendalian Manajemen (SPM) yang selanjutnya akan berpengaruh pada kinerja organisasi UMKM. Untuk menguji hubungan antara pembentukan strategi dan penggunaan Sistem Pengendalian Manajemen, penelitian ini menggunakan Simons' framework yang dikenal sebagai levers of control. Framework yang diadopsi dari Simons (1995) ini terdiri dari empat forms (belief, boundary, diagnostic dan interactive) yang digunakan dalam praktik SPM akan tetapi penelitian ini hanya berfokus pada penggunaan sistem pengendalian interactive dan diagnostic karena dianggap memiliki hubungan yang mendalam dengan sebuah perumusan strategi strategi (Kober et al. 2007).

\section{KAJIAN PUSTAKA}

Formulasi Strategi dan Kinerja Organisasi UMKM

Pengukuran terhadap kinerja organisasi secara garis besar masih menjadi permasalahan serta perdebatan yang klasik karena kinerja organisasi bersifat multi dimensi yang didalamnya mencakup berbagai macam tujuan serta tipe organsiasi (Bhargava dkk., 1994). Hal ini membuat kinerja dikonseptualisasikan dalam berbagai macam cara serta metoda yang juga memiliki pengukuran yang beragam. Penelitian-penelitian yang ada sebelumnya banyak yang menyatakan bahwa perencanaan strategis memiliki hubungan yang positif dengan kinerja organisasional yang terbagi menjadi dua aliran utama, yaitu (1) perencanaan strategis meningkatkan keuntungan usaha atau kinerja keuangan organisasi dan (2) perencanaan strategis digunakan sebagai kunci menuju sukses serta meningkatkan kinerja organisasi (Rue dan Ibrahim, 1998). Temuan lain juga yang menunjukkan bahwa perencanaan strategis yang efektif dapat meningkatkan profit (berhubungan 
positif) ketika sumber data dari kinerja digunakan karena diukur melalui refrensi serta dokumen yang tersedia pada organisasi (Miller, 1994).

Dengan kata lain, sebuah perencanaan strategis mengenai formulasi dari strategi yang disesuaikan dengan perubahan-perubahan serta tantangan lingkungan bisnis yang dinamis, dapat menstimulasi atau mengarahkan seluruh elemen organisasi untuk mencapai tujuan serta meningkatkan kinerja organisasional. Sehingga dirumuskan sebuah hipotesis yang menyatakan hubungan antara perencanaan strategis dengan kinerja organisasi.

H1: Perencanaan strategis dalam formulasi strategi memiliki hubungan dengan kinerja organsiasi UMKM Sistem Pengendalian Manajemen Berbasis Levers of Control

Sistem Pengendalian Manajemen (SPM) merupakan sebuah proses yang digunakan dalam perusahaan untuk mengarahkan seluruh elemen perusahaan untuk mengimplementasikan strategi dan atau mencapai tujuan organisasi. Anthony dan Govindarajan (2004) mengungkapkan bahwa Sistem Pengendalian Manajemen digunakan oleh para manajer agar dapat mempengaruhi para anggota organisasi untuk melaksanakan aktivitas-aktivitas organisasi yang mengarah pada implementasi strategi organisasi. Selain itu, desain sistem pengendalian organisasi diharapkan berguna sebagai kontrol atau pengaturan aktivitas tersebut agar sesuai dengan yang dikehendaki oleh pimpinan atau manajer organisasi (Anthony dan Govindarajan, 2004; Simons, 1990).

Untuk memperoleh kesuksesan dalam implementasi strategi sangat bergantung pada bagaimana proses pengendalian manajemen dijalankan. Keefektifan suatu sistem pengendalian dalam mencapai tujuan organisasi atau suksesnya implementasi strategi ditentukan dan dilihat dari seberapa jauh sistem pengendalian tersebut sesuai dengan karakteristik organisasi. Pondeville (2000) melalui pendekatan kontijensi mengungkapkan bahwa sistem pengendalian manajemen akan sangat menunjang dalam pencapaian tujuan dan implementasi strategi apabila desain dan prosesnya sesuai dengan kondisi lingkungan organisasi. Hingga saat ini, telah banyak literatur yang telah mengeksplorasi bahwa strategi berpengaruh pada sistem pengendalian manajemen dari berbagai sudut pandang serta pendekatan. Chenhall (2005) misalnya, mengungkapkan bahwa konten dari strategi mungkin berhubungan dengan hasil dari proses strategi tersebut. Dengan kata lain, strategi sangat dekat hubungannya dengan apa yang harus dilakukan oleh perusahaan untuk mencapai kinerja perusahaan yang maksimal dan untuk membatasi view dari strategi yang menjadi tujuan perusahaan. Oleh karena itu, konseptualisasi SPM seharusnya dilakukan dengan pendekatan yang terstruktur agar sejalan dengan proses implementasi strategi perusahaan.

Banyaknya hasil penelitian yang menghubungkan penggunaan Sistem Pengendalian Manajemen dengan strategi masih menimbulkan keresahan persepsi dan dipertanyakan karena banyaknya definisi serta konseptualisasi dari strategi itu sendiri. Langfield-Smith (1997) mengatakan bahwa banyak penelitian yang mengungkapkan hasil terkait hubungan antara SPM dan strategi berdasarkan research view masih ambigu dan terkadang kontradiktif. Penelitian ini menguji hubungan antara perencanaan strategis dalam pembentukan strategi yang disebutkan pada pembahasan sebelumnya (emergent dan intended strategy) dengan penggunaan sistem pengendalian manajemen berdasarkan pada Simons' framework (1995) yang disebut levers of control. Terdapat empat bentuk penggunaan praktis MCS pada levers of control, yaitu: (1) Belief control system yang berfungsi untuk menyediakan sebuah momentum dan pedoman bagi perilaku oportunistik organisasi; (2) Boundary control system mengendalikan risiko harus dihindari dan berfungsi untuk mengembangkan kreativitas individual yang didefinisikan dengan baik dalam pembatasan kebebasannya; (3) Diagnostic control system mengendalikan variabel-variabel kritikal dari kinerja dan fungsinya adalah untuk memberikan motivasi, sumber daya dan informasi untuk memastikan bahwa strategi dan tujuan perusahaan akan tercapai; (4) Interactive control system digunakan untuk mengendalikan ketidakpastian strategik dan berfungsi memfokuskan perhatian organisasi terhadap ketidakpastian tersebut dan sebagai proses pembelajaran sehingga bisa dengan cepat mendorong adanya inisiatif dan strategi yang baru.

Penelitian ini hanya berfokus pada penggunaan sistem pengendalian interactive dan diagnostic karena dianggap memiliki hubungan yang mendalam dan lebih menjelaskan hubungan antara strategi dan SPM 
(Kober et al. 2007). Selain itu, penggunaan kedua sistem pengendalian tersebut dianggap paling relevan untuk meningkatkan kinerja perusahaan. Secara formal, hubungan antara strategi dan Sistem Pengendalian Manajemen telah terlihat dalam bentuk yang pasif. Hal tersebut berarti bahwa Sistem Pengendalian Manajemen merupakan hasil akhir dari strategi organisasi (Kober dan Paul, 2007). Konsep proses pembentukan emergent strategy yang diteliti bersama hasil dari levers of control, menginvestigasi kepraktisan diagnostic control system dan interactive control system dalam proses pembentukan strategi tersebut (Mintzberg, 1985, 1994; Simons, 1990, 1994, 1995). Penelitian-penelitian tersebut secara teoritis dan empiris memberi dukung terhadap bagaimana penggunaan praktis dari sistem pengendalian diagnostic dan interactive dalam sebuah perusahaan. Sistem pengendalian diagnostic akan membantu sebuah organisasi untuk mencapai strategi yang telah dibentuk atau diformulasikan, sedangkan interactive control system akan membantu organisasi untuk mengkomunikasikan agenda strategisnya dan pencapaian organisasi dalam fitur ketidakpastian yang kemungkinan muncul dari proses pengembangan strategi organisasi. Simons (1995) menguji bahwa interactive control system akan mendukung dialog dan perubahan dalam jangka waktu yang lebih lama serta interactive control system akan menciptakan sifat kompetitif dalam sebuah organisasi untuk memiliki inovasi serta beradaptasi dengan lingkungan bisnisnya. Berdasarkan pembahasan tersebut, dapat disimpulkan bahwa interactive control system akan memberikan penyesuaian dalam sebuah emergent strategy yang muncul secara spontan.

Perubahan dalam sebuah hubungan tradisional antara proses pembentukan strategi, implementasi strategi, dan evaluasi penggunaan sistem pengendalian manajemen, telah ditegaskan oleh para peneliti-peneliti lain yang telah menguji hubungan yang sama. Marginson (2002) misalnya, dia menemukan bahwa persepsi manajerial dalam praktek Sistem Pengendalian Manajemen akan disesuaikan ke dalam pembentukan strategi atau pengimplementasian strategi. Dapat dikatakan bahwa strategi akan memiliki pengaruh yang sangat dalam dan besar terhadap Sistem Pengendalian Manajemen. Kober (2007) menemukan bahwa mekanisme SPM yang digunakan secara interaktif akan memfasilitasi perubahan strategi dan ketika perubahan tersebut terjadi, mekanisme MCS akan ikut berubah dan disesuaikan dengan proses strategi tersebut. Simons (1994) menemukan bahwa diagnostic control system akan membantu organisasi untuk mengarahkan kepada strategi organisasi tersebut, dan interactive control system akan membantu organsiasi untuk mengkomunikasikan faktor kritikal pencapaian strategi organisasi. Berdasarkan hasil yang ditemukan oleh Simons (1994) tersebut, Chenhall dan Morris (1995) meneliti dan menemukan bahwa proses pengambilan keputusan sejalan dengan interactive control system dan secara efektif akan terbukti ketika dikombinasikan dengan diagnostic control system (Henri, 2006).

Widener (2007) berpendapat bahwa perusahaan akan menggunakan secara bersamaan sistem penegndalian diagnostic dan interactive sehingga para top manajer bisa menjalankan sistem pengendalian yang interaktif dengan baik. Hasil penelitian Mintzberg (1978) lebih lanjut membedakan bahwa intended strategy menjadi tujuan sebuah perusahaan dan emergent strategy menjadi strategi yang dibentuk secara spontan dalam perusahaan. Kebijakan konvensional mengenai hubungan antara strategi organisasi dengan sistem pengendalian manajemen mengatakan bahwa pembentukan strategi dan implementasinya akan memberikan pengaruh yang signifikan terhadap bagaimana sistem pengendalian akan digunakan dan hal ini konsisten dengan teori kontijensi yang menjelaskan bahwa SPM perlu dicocokkan dan disesuaikan dengan strategi organisasi.

Penelitian-penelitian terdahulu telah banyak mengungkapkan bahwa penggunaan sistem pengendalian manajemen memiliki pengaruh terhadap kinerja organisasi (Fisher, 1998; Govindarajan, 1988; Simons, 1990) serta menunjukkan bukti bahwa efektivitas pengendalian manajemen yang digunakan oleh organisasi berpengaruh secara signifikan terhadap peningkatan kinerja organisasi tersebut (Simons, 1990, 1991; Syafruddin, 2001). Dengan kata lain, sebuah sistem pengendalian yang dioperasionalkan secara efektif oleh manajer atau pimpinan organisasi dapat mempengaruhi anggota organisasi tersebut untuk meningkatkan kinerja organisasional. Pernyataan tersebut memotivasi penelitian ini untuk kembali melihat pengaruh dari 
penggunaan sistem pengendalian manajemen dengan peningkatan kinerja organisasi yang berhubungan dengan strategi perusahaan. Sehingga untuk memberikan gambaran mengenai hubungan antara SPM adopsian dari levers of Control milik Simons (1995) yang berfokus pada penggunaan interactive dan diagnostic control system dengan kinerja organsiasi, maka penelitian ini mengemukakan hipotesis penelitian sebagai berikut:

$\mathrm{H} 2$ : Perencanaan strategis dalam formulasi strategi UMKM memiliki hubungan tidak langsung dengan kinerja organsiasi UMKM melalui sistem pengendalian manajemen berbasis levers of control.

\section{METODE PENELITIAN}

Sampel dan Data Penelitian

Penelitian ini menggunakan metoda survei dalam pengumpulan data subyek yang berupa opini, sikap, pengalaman, atau karakteristik seseorang yang menjadi seubyek penelitian. Survei dilakukan dengan menggunakan kuesioner sebagai instrumen pengukuran yang didistribusikan melalui hand-tohand atau secara langsung dan kolektif di tempat. Untuk memperoleh desain koesioner yang efektif dan efisien, terlebih dahulu dilakukan pilot test untuk mengetahui validitas dan reliabilitas instrumen dan menaksir tingkat pemahaman serta durasi yang dibutuhkan responden untuk mengisi kuesioner. Pilot test dianggap penting dalam penelitian di bidang ilmu sosial sebagai suatu bentuk usaha meningkatkan response rate terhadap survei yang dilaksanakan (Markus, 1996).

Sampel yang digunakan sebagai responden dalam penelitian ini adala para manajer atau pimpinan UMKM yang bergerak diusaha manufaktur (produksi) dan terdaftar di Dinas Koperasi dan UKM Kota Samarinda pada tahun 2017. Alasan pemilihan sampel tersebut karena UMKM yang bergerak di usaha produksi barang (manufaktur) merupakan bisnis yang berada pada lingkungan industri dinamis sehingga perubahan lingkungan yang tidak pasti dan dinamis tersebut menuntut para pelaku bisnis dalam industri tersebut untuk melakukan inovasi serta membentuk strategi yang bertujuan untuk menyesuaikan dengan perubahan yang terjadi.

Data dikumpulkan melalui hand-to-hand survey kepada kontroler atau unsur pimpinan setiap UMKM. Kontroler dipilih sebagai responden karena mereka diasumsikan memiliki pengetahuan yang memadai tentang sistem pengendalian manajemen sebuah organisasi bisnis yang mereka pimpin
(Jermias dan Gani, 2004). Sebanyak 134 kuesioner yang dikirim ke UMKM yang tersebar di Kota Samarinda, tidak semua respon yang terkumpul dapat digunakan karena tidak lengkap serta kurangnya informasi yang diberikan sehingga tidak dapat dilakukan analsisis lebih lanjut. Dari total kuesioner yang terkumpul, hanya 49 kuesioner yang layak dan semuanya dapat digunakan untuk analisis lebih lanjut. Hal ini menunjukkan tingkat respon sebesar $37,12 \%$. Tingkat respon penelitian ini relatif cukup tinggi karena pada umumnya tingkat respon survei di Indonesia adalah sekitar 10-20\% (Kurnianingsih dan Indriantoro 2001; Mardiyah dan Gudono, 2001; Lau dan Sholihin, 2005).

Pengukuran Variabel

Perencanaan Strategis (Formulasi Strategi)

Pengukuran yang digunakan untuk dimensi pada konstruk perencanaan stratgeis diadopsi dari instrumen Rue dan Ibrahim (1998) yang merupakan penyempurnaan dari instrumen Shrader dkk. (1989). Instrumen tersebut berisi tentang misi, tujuan yang ingin dicapai, pemelihan dan pengembangan strategi, dan penentuan pedoman kebijakan organisasi. Konstruk perencanaan strategis terdiri atas 17 item pertanyaan yang diukur menggunakan skala Likert 1 sampai dengan 7.

\section{Sistem Pengendalian Manajemen}

Sistem pengendalian manajemen berbasis levers of control diukur dengan menggunakan instrumen yang diadaptasi dari versi Vandenbosch (1999) yang berpedoman pada Simon's Framework. Instrumen tersebut dikembangkan secara original untuk mengukur penggunaan Executive Support Systems (ESS) dan berdasarkan pada beberapa dimensi penggunaan sistem pengendalian diagnostic dan interactive. Terdapat delapan indikator yang dijabarkan dalam delapan item serta diukur dengan menggunakan skala Likert 1-7.

\section{Kinerja Organisasional}

Kinerja organisasional didefinisikan sebagai tingkat pencapaian dari tujuan yang telah ditetapkan yang dilihat dalam aspek keuangan maupun non keuangan (Bisbe dan Otley, 2004). Kinerja organisasional diukur dengan instrumen yang dikembangkan oleh Govindarajan dan Fisher (1990) yang terdiri dari 6 item yang dikomposit. Dalam rangka memperoleh cross-validation maka penelitian ini mengikuti prosedur Bisbe dan Otley (2004). Selain ketujuh indikator di atas, responden juga diminta menilai tingkat kinerja secara keseluruhan (overall global rating of performance). Ukuran kinerja komposit berkorelasi positif dan signifikan (koefisien 
korelasi $=0,914$ dan signifikan pada nilai $\mathrm{p}=0,000$ ) dengan item kinerja keseluruhan tersebut.

Teknik Analisis dan Pengujian Hipotesis

Teknik analisis data yang digunakan untuk melakukan pengujian hipotesis menggunakan analisis Partial Least Square dengan program Warp-PLS versi 2.0. Pemilihan alat analisis ini dianggap tepat karena memiliki kelebihan-kelebihan yang menunjang penelitian ini. Hair dkk. (2010) mengungkapkan bahwa kelebihan menggunakan SEM-PLS adalah sesuai untuk model penelitian yang menggunakan variabel yang tidak dapat diukur secara langsung (latent variables) seperti dalam penelitian ini. Selain itu, analisis SEM juga dapat digunakan untuk menguji secara simultan multiple dependence seperti model penelitian ini. Kelebihan selanjutnya adalah SEM-PLS dapat mengestimasi model yang cukup kompleks dengan ukuran sampel yang tergolong kecil (Kock, 2011).

\section{HASIL DAN PEMBAHASAN}

Uji Validitas dan Reliabilitas

Sesuai dengan prosedur pengujian SEM-PLS, maka evaluasi validitas konvergen konstruk menggunakan indikator berupa factor loading dan Average Variance Extracted atau AVE (Kock, 2010, 2011; Sholihin dan Ratmono, 2014). Hasil evaluasi outer model yang dijalankan menggunakan program WarpPLS pada tabel 2 di bawah menunjukkan kriteria validitas konvergen telah terpenuhi yaitu loading yang dihasilkan lebih besar dari 0,70 serta nilai AVE lebih besar dari 0,50. Kedua nilai tersebut sudah memenuhi rule of thumb yang dikemukakan oleh Kock (2010, 2011) dan Sholihin dan Ratmono (2014).

Tabel 1. Validitas dan Reliabilitas

\begin{tabular}{|c|c|c|c|c|}
\hline \multirow[b]{2}{*}{ Konstruk } & \multicolumn{2}{|c|}{ Validitas } & \multicolumn{2}{|c|}{ Reliabilitas } \\
\hline & $\begin{array}{l}\text { Loading } \\
\text { Range }\end{array}$ & $A V E$ & $\begin{array}{l}\text { Composite } \\
\text { Reliability }\end{array}$ & $\begin{array}{c}\text { Cronbach } \\
\text { Alpha }\end{array}$ \\
\hline $\begin{array}{l}\text { Formulasi } \\
\text { Strategi }\end{array}$ & $\begin{array}{l}0.82- \\
0.90\end{array}$ & 0.763 & 0.982 & 0.980 \\
\hline $\begin{array}{l}\text { Sistem } \\
\text { Pengendalian } \\
\text { Manajemen }\end{array}$ & $\begin{array}{c}0.78- \\
0.89\end{array}$ & 0.727 & 0.955 & 0.946 \\
\hline $\begin{array}{l}\text { Kinerja } \\
\text { Organisasi }\end{array}$ & $\begin{array}{c}0.75- \\
0.93 \\
\end{array}$ & 0.738 & 0.944 & 0.927 \\
\hline
\end{tabular}

Matriks korelasi yang ditunjukkan pada tabel 3 menunjukkan adanya hubungan positif yang cukup kuat antara variabel formulasi strategi dengan Sistem Pengendalian Manajemen yang ditunjukkan dengan koefisien korelasi sebesar 0.613 serta signifikan. Begitu juga dengan hubungan antara formulasi strategi dengan kinerja organisasional yang menunjukkan nilai koefisien korelasi sebesar 0.667 serta signifikan. Koefisien korelasi antara SPM dengan kinerja organisasional juga menunjukkan bahwa terdapat hubungan positif antara keduanya denga nilai sebesar 0.597 dan signifikan.

Hasil ini menunjukkan adanya keterdukungan terhadap hipotesis 1 (H1) serta indikasi awal dukungan terhadap hipotesis mediasi (H2) karena hubungan tidak langsung atau peran mediasi mensyaratkan adanya korelasi signifikan antara variabel independen, pemediasi, dan dependen (Baron dan Kenny, 1986).

Tabel 2. Korelasi Antar Konstruk

\begin{tabular}{lccc}
\hline \multicolumn{1}{c}{ Konstruk } & $\begin{array}{c}\text { Formulasi } \\
\text { Strategi }\end{array}$ & SPM & Kinerja \\
\hline Formulasi Strategi & $\mathbf{0 . 8 7 3}$ & $0.613 * *$ & $0.667 * *$ \\
Sistem Pengendalian & $0.613 * *$ & $\mathbf{0 . 8 5 3}$ & $0.597 * *$ \\
Manajemen & $0.667 * *$ & $0.597 * *$ & $\mathbf{0 . 8 5 9}$ \\
Kinerja Organisasi & &
\end{tabular}

\section{Pengujian Hipotesis Penelitian}

Penelitian ini melakukan pengujian hubungan langsung antara formulasi strategi dalam perencanaan strategis dengan kinerja organisasional UMKM (H1). Selain itu, penelitian ini juga menguji hubungan tidak langsung antara formulasi strategi dengan kinerja organisasi melalui varbael mediasi penggunaan Sistem Pengendalian Manajemen (SPM) berbasis LOC. Dibawah ini akan dijelaskan mengenai pengujian tiap-tiap hipotesis yang dikemukakan dalam penelitian.

Keputusan mengenai keterdukungan hipotesis penelitian didasarkan pada hasil evaluasi model struktural pada SEM-PLS selanjutnya yaitu dengan melihat nilai koefisien jalur $(\beta)$ dan signifikansi yang ditunjukkan ( $p$-value). Didukungnya hipotesis penelitian dinyatakan ketika hasil penelitian menolak $\mathrm{H}_{0}\left(\mathrm{H}_{\mathrm{a}}\right.$ terdukung) dengan $p$-value $<0,01$ (untuk level signifikansi 1\%) dan $p<0,05$ (untuk level signifikansi $5 \%)$.

Pada penjelasan sebelumnya, telah dikemukan indikasi keterdukungan terhadap hipotesis 1 penelitian bahwa dari nilai koefisien $(\beta)$ menunjukkan nilai yang positif dan signifikan. Keterdukungan hasil yang ditinjau dari nilai serta signifikan yang dihasilkan dapat dilihat pada Gambar 1.

Pengujian terhadap hipotesis mediasi pada model struktural penelitian dilakukan melalui pendekatan Baron dan Kenny (1986) yang biasa disebut pendekatan step-wise. Untuk menguji model mediasi penelitian, Baron dan Kenny (1986) serta 
Sholihin dan Ratmono (2013) mengatakan bahwa terdapat dua langkah yang perlu dilakukan dalam pengujian tersebut yaitu:

1) Melakukan estimasi untuk hubungan langsung antara variabel dependen dengan variabel independen penelitian.

2) Melakukan estimasi hubungan tidak langsung dengan memasukkan variabel mediasi penelitian.

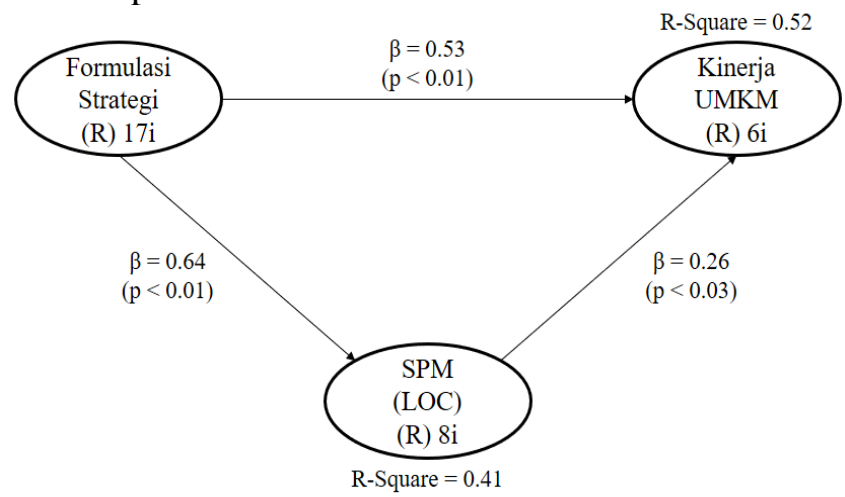

Gambar 1. Evaluasi Model Struktural

Hasil pengujian model mediasi disajikan pada tabel 4. Hasil estimasi model (1) dan (2) menunjukkan kriteria goodness of fit telah terpenuhi yaitu nilai APC dan ARS menunjukkan hasil yang signifikan secara statistic dan AVIF kurang dari 5. Angka tersebut telah memenuhi role of thumb seperti yang dikemukakan oleh Kock $(2010,2011)$ dan Hair dkk. (2014). Hasil pada tabel 4 di bawah memberikan bukti bahwa persyaratan untuk pengujian mediasi telah terpenuhi dengan nilai masing-masing jalur menunjukkan hasil yang positif dan signifikan.

Hasil pengujian menunjukkan bahwa koefisien hubungan langsung (direct effect) Formulasi strategi terhadap kinerja (jalur c) pada model (1) adalah sebesar 0.697 dan signifikan. Hasil estimasi model (2) menunjukkan koefisien indirect effect Formulasi strategi terhadap kinerja (jalur c") turun menjadi 0.526 namun tetap signifikan. Hal ini memberikan kesimpulan bahwa peran mediasi variabel SPM dalam hubungan antara formulasi strategi dengan kinerja UMKM adalah memediasi sebagian (partial mediation). Baron dan Kenny (1986) menjelaskan bahwa jika hasil yang diperoleh adalah mediasi sebagian, maka variabel mediasi penelitian (di penelitian ini SPM) bukan satu-satunya pemediasi hubungan variabel yang diobservasi namun masih terdapat faktor lain yang memediasi.

Secara keseluruhan, pengujian hipotesis penelitian menunjukkan hasil yang sesuai dengan prediksi peneliti. Hasil empiris yang ditemukan mengindikasikan bahwa baik hubungan langsung (Formulasi Strategi $\rightarrow$ Kinerja UMKM) maupun tidak langsung (Formulasi Strategi $\rightarrow$ SPM $\rightarrow$ Kinerja UMKM) adalah positif dan signifikan serta membuktikan bahwa semua hipotesis (H1 dan $\mathrm{H} 2)$ yang diajukan dalam penelitian tidak dapat ditolak atau dengan kata lain terdukung.

Tabel 3. Hasil Pengujian Hipotesis

\begin{tabular}{lcccc}
\hline \multirow{2}{*}{ Jalur } & \multicolumn{2}{c}{ Direct Effect (1) } & \multicolumn{2}{c}{ Indirect effect (2) } \\
\cline { 2 - 4 } & Koefisien & $\begin{array}{c}\text { p- } \\
\text { value }\end{array}$ & Koefisien & $\begin{array}{c}\text { p- } \\
\text { value }\end{array}$ \\
\hline $\begin{array}{l}\text { Formulasi } \\
\text { Strategi } \rightarrow \\
\text { SPM }\end{array}$ & & & 0.637 & 0.001 \\
$\begin{array}{l}\text { SPM } \rightarrow \\
\text { Kinerja }\end{array}$ & & & & \\
$\begin{array}{l}\text { Formulasi } \\
\text { Strategi } \rightarrow\end{array}$ & 0.697 & 0.004 & 0.526 & 0.032 \\
Kinerja & & & & \\
$\begin{array}{l}\text { Indikator } \\
\text { Model Fit }\end{array}$ & & & & \\
Average & & & & \\
$\begin{array}{l}\text { Path } \\
\text { Coefficient }\end{array}$ & 0.697 & 0.001 & 0.475 & 0.001 \\
(APC) & & & & \\
Average \\
R-Square \\
(ARS)
\end{tabular}

\section{KESIMPULAN DAN SARAN}

Penelitian ini disusun sebagai usaha untuk memberikan jawaban atas fenomena terkait bagaimana penggunaan dari sistem pengendalian manajemen (MCS) pada hubungan antara strategic planning dengan kinerja organisasi UMKM. Dari hasil penelitian disimpulkan bahwa sebuah perencanaan strategis yang baik akan mengarah pada peningkatan kinerja organisasional bagi UMKM. Hasil yang ditunjukkan memberikan pemahaman yang sangat bernilai bagi pengembangan UMKM di Kota Samarinda karena dengan merencanakan strategi dengan baik, maka organisasi UMKM dapat meningkatkan kinerja secara baik terlebih lagi ketika UMKM mengaplikasikan Sistem Pengendalian Manajemen yang juga dapat meningkatkan peranan formulasi strategi untuk meningkatkan kinerja.

Selanjutnya, perencanaan strategis yang difokuskan pada pembentukan dari srategi (emergent dan intended) memiliki hubungan yang postif dengan penggunaan MCS yang dijabarkan melalui diagnostic 
dan interactive control system. Hal tersebut dapat dihubungkan dengan perlunya penyesuaian sistem pengendalian manajemen dengan strategi yang dibentuk oleh organisasi. Hasil penelitian mengindikasikan penggunaan MCS memiliki hubungan dengan strategi dan kinerja organisasi. Hal ini memungkinkan pembentukan strategi yang dilakukan oleh organsiasi sejalan atau akan mempengaruhi pilihan sistem penegndalian yang sesuai dan mengarahkan para anggota organisasi untuk melaksanakan aktivitas-aktivitas yang sesuai dengan strategi perusahaan sehingga berujung pada peningkatan kinerja organisasional UMKM di Kota Samarinda.

Penelitian ini masih memiliki keterbatasan khususnya pada pembangunan konstruk di tiap variabel penelitian. Sehingga untuk penelitian kedepannya perlu ditelaah lebih dalam menyangkut konstruk yang benar-benar dapat mewakili variabel yang diteliti sehingga dapat memperoleh hasil yang dapat lebih diandalkan. Selain itu, keterbatasan pada literatur yang menjelaskan hubungan erat antar variabel juga lepas dari sorotan dalam penelitian ini, sehingga perlu disempurnakan dengan memperbanyak konsep maupun teori yang menjelaskan hubungan antara variabel penelitian.

\section{REFERENSI}

[1] Allison dan Kaye (2005). Perencanaan Strategis Bagi Organisasi Nirlaba. Yayasan Obor Indonesia, Jakarta.

[2] Amstrong, M. (1994). Performance Management. Kogan Page LTD, London, U.K.

[3] Anthony, R.N., dan Govindarajan, V. (2004). Management Control System. McGraw-Hill, New York, USA.

[4] Bhargava, M., Dubelaar, C., dan Ramaswari, S. (1994). Reconciling Diverse Measures of Performance: A Conceptual Framework Test of Methodology. Journal of Business Research. Volume 31.

[5] Bhimani, A. dan Langfield-Smith, K. (2007). Structure, Formality, and the Importance of Financial and Non-Financial Information in Strategy Development and Implementation. Management Accounting Research. Volume 18.

[6] Chenhall, R.H. (2005). Content and Process Approaches to Studying Strategy and Management Control System. Oxford University Press, Oxford, U.K.
[7] Daneels, E. (2002). The Dynamics of Product Innovation and Warm Competences. Strategic Management Journal. Volume 23.

[8] Dent, J.F. (1990). Strategy, Organization, and Control: Some Possibilities for Accounting Research. Accounting, Organization and Society. Volume 15.

[9] Ferdinand, Augusty. (2002). Structural Equation Modelling Dalam Penelitian Manajemen. Program Magister Manajemen, Universitas Diponegoro, Semarang.

[10] Fisher, J.G. (1998) Contingency Theory, Management Control System and Firm Outcomes: Past Result and Future Directions. Behavioral Research in Accounting. Volume 10.

[11] Govindarajan, V. (1988). A Contingency Approach to Strategy Implementation at the Business-Unit Level: Integrating Administrative Mechanisms with Strategy. Academy of Management Journal. Volume 31.

[12] Govindarajan, V., dan Fisher, J. (1990). Strategy, Control System and Resource Sharing: Effect on Business-Unit Performance. Academy of Management Journal. Volume 33.

[13] Hair, J.F. et al. (2006). Multivariate Data Analysis. Edisi Keenam. Pearson Education Inc. New Jersey, USA.

[14] Henri, J.F. (2006). Management Control System and Strategy: A Resource-Based Perspective. Accounting, Organization and Society. Volume 31.

[15] Hoque, Z., dan James, W. (2000) Linking Balanced Scorecard Measures to Size and Market Factors: Impact on Organizational Performance. Journal of Management Accounting Research. Volume 12.

[16] Jumaili, S., dan Gudono. (2006). Hubungan Komponen Sistem Pengendalian Manajemen Terhadap Kinerja Kualitas dan Konsekuensi Terhadap Kinerja Keuangan. Simposium Nasional Akuntansi IX. Padang, Indonesia.

[17] Kerzner, H. (2001). Strategic Planning for Project Management Using A Project Management Maturity Model. Jhon Wiley and Son, Inc., New York, USA.

[18] Kober, R., Ng, J., dan Paul, B.J. (2007). The Interrelationship between Management Control Mechanism and Strategy. Management Accounting Research. Volume 18.

[19] Langfield-Smith, K. (1997). Management Control System and Strategy: A Critical 
Review. Accounting, Organization and Society. Volume 22

[20] Margison, D.E.W. (2002). Management Control System and Their Effects on Strategy Formulation at Middle Management Level: Evidence from A U.K. Organization. Strategic Management Journal. Volume 23.

[21] Merchant, K.A. dan Otley, D.T. (2006). A Review of the Literature on Control and Accountability. Elsevier Press.

[22] Miller, C.C., dan Cardinal, L.B. (1994). Strategic Planning and Firm Performance: A Synthesis of More than Decades of Research. Academy of Management Journal. Volume 37.

[23] Mintzberg, H. (1994). The Fall and Rise of Strategic Planning. Harvard Business Review. Prentice Hall International.

[24] Mintzberg, H., dan Waters.J.A. (1985). Of strategies: Deliberate and Emergent. Strategic Management Journal. Volume 6.

[25] Norreklit, H. (2000). The Balance on the Balanced Scorecard - A Critical Analysis of Some of Its Assumptions. Management Accounting Research. Volume 11.

[26] Otley, D.T. (1999). Performance Management: A Framework for Management Control System Research. Management Accounting Research. Volume 10.

[27] Pearce, J.A., Freemen, E.B., dan Robinson, R.B. (1987). The Tenous Link between Formal Strategic Planning and Financial Performance. Academy of Management Review. Volume 12.

[28] Pondenville, S.M. (2000). The Control Systems in the Environmental Management Framework. Working Paper.

[29] Porter, M.E. (1999). Competitive Strategy: Creating and Sustaining Superior Performance. Free Press, New York, USA.

[30] Richard, P.J., Devinney, T.M., Yip, G.S., dan Johnson, G. (2009) Measuring Organizational Performance: Towards Methodological Best Practice. Journal of Management. Volume 43.

[31] Roberts, J. (1990). Strategy and Accounting in A U.K. Conglomerate. Accounting, Organizations and Society. Volume 15.

[32] Robinson, R.P., dan Pearce, J.A. (1988). Planned Patterns of Strategic Behavior and Their Relationship to Business-Unit Performance. Strategic Management Journal. Volume 9.

[33] Rue, L.W., dan Ibrahim, N.A. (1998). The Relationship between Planning Sophistication and Performance in Small Business. Journal of Small Business Management.

[34] Shrader, C.B., Mulford, C.L., dan Blackburn, V.L. (1989). Strategic and Operational Planning Uncertainty, and Performance in Small Firm. Journal of Small Business. 